\title{
OTIMIZAÇÃO DE UMA COLUNA DE DESTILAÇÃO AZEOTRÓPICA HOMOGÊNEA APLICADA À OBTENÇÃO DE ETANOL ANIDRO
}

\author{
T. G. das NEVES ${ }^{1}$, S. B. B. L. VILLAR ${ }^{1}$, J. N. SILVA $^{1}$ e R. P. BRITO ${ }^{1}$ \\ ${ }^{1}$ Universidade Federal de Campina Grande, Departamento de Engenharia Química \\ E-mail para contato: thiago.gdn@ hotmail.com
}

\begin{abstract}
RESUMO - Quando a destilação convencional não possibilita uma separação eficiente de uma mistura azeotrópica, geralmente utiliza-se a destilação azeotrópica homogênea (destilação extrativa). O solvente utilizado nesse método altera os coeficientes de atividade da fase líquida e aumenta a volatilidade relativa dos componentes de interesse. Esse trabalho tem por objetivo simular, analisar e otimizar no Aspen Plus ${ }^{\circledR}$ um processo de destilação extrativa para a produção de etanol anidro, usando etilenoglicol como solvente. Por se tratar de uma separação de alta pureza, simulações no estado transiente com o Aspen Plus Dynamics ${ }^{\circledR}$ mostraram que a coluna apresenta longo tempo de resposta às perturbações e comportamento não linear. Com o auxílio da ferramenta Optimization do Aspen Plus ${ }^{\circledR}$ foi possível uma redução de aproximadamente $9,6 \%$ do consumo energético da coluna em relação ao processo inicial, que foi baseado em dados da literatura.
\end{abstract}

\section{INTRODUÇÃO}

Destilação é o processo mais importante de separação física, sendo utilizada em $95 \%$ das separações de fluidos na indústria química e é responsável por 3\% do consumo da energia mundial (Engelien e Skogestad, 2004). Neste contexto, controlar e otimizar a eficiência energética dos processos com esse tipo de separação é uma ótima alternativa para diminuir custos e evitar desperdícios. Como a separação por destilação ocorre devido a diferenças nas temperaturas de ebulição, se os componentes possuem tais temperaturas próximas, a destilação convencional não se torna eficiente. Além disso, para determinadas misturas pode também ocorrer formação de um ponto azeotrópico, onde a composição da fase líquida é igual à composição da fase de vapor. Assim, é impossível obter produtos com pureza maior que a da composição azeotrópica em um processo de destilação convencional (Oliveira, 2009).

Uma das formas bastante utilizadas atualmente é a destilação azeotrópica: homogênea (destilação extrativa) e heterogênea. A destilação extrativa é menos complexa e mais amplamente usada que a destilação azeotrópica heterogênea por causa da ausência de azeótropos e pelo fato do solvente poder ser recuperado por destilação simples. Esse método utiliza grandes quantidades de solvente, o qual altera os coeficientes de atividade da fase líquida da mistura, e dessa forma aumentando a volatilidade relativa dos componentes de interesse (Seader e Henley, 1998).

Uma das maiores aplicações do processo de destilação extrativa é a produção de álcool anidro. Dentre as aplicações do álcool anidro, destaca-se sua utilização como combustível, 
sendo misturado à gasolina para operar com máquinas de ignição. O Brasil permite a mistura de etanol anidro na gasolina, além da vasta difusão dos automóveis bicombustíveis que podem funcionar com etanol (Gil et al., 2012). Um dos solventes mais usados para a desidratação de etanol é o etilenoglicol (Dias et al., 2009). A relação solvente/azeótropo deve ser cuidadosamente escolhida, para não elevar a quantidade de energia requerida, aumentando a vazão de líquido na coluna, diminuindo a eficiência e, portanto, aumentando a quantidade de estágios requeridos (Wolf e Brito, 1995).

O presente trabalho tem como principal objetivo simular, analisar e otimizar o processo de destilação extrativa para a produção de etanol anidro, usando etilenoglicol como solvente.

\section{METODOLOGIA}

A simulação da obtenção de etanol anidro através da destilação extrativa foi baseada em trabalhos já publicados (Junqueira et al., 2012; Meirelles et al., 1992; Oliveira, 2009; Gil et al., 2008). Foi realizada a construção do fluxograma do processo de desidratação do etanol no Aspen Plus ${ }^{\circledR}$, de acordo com a Figura 1.

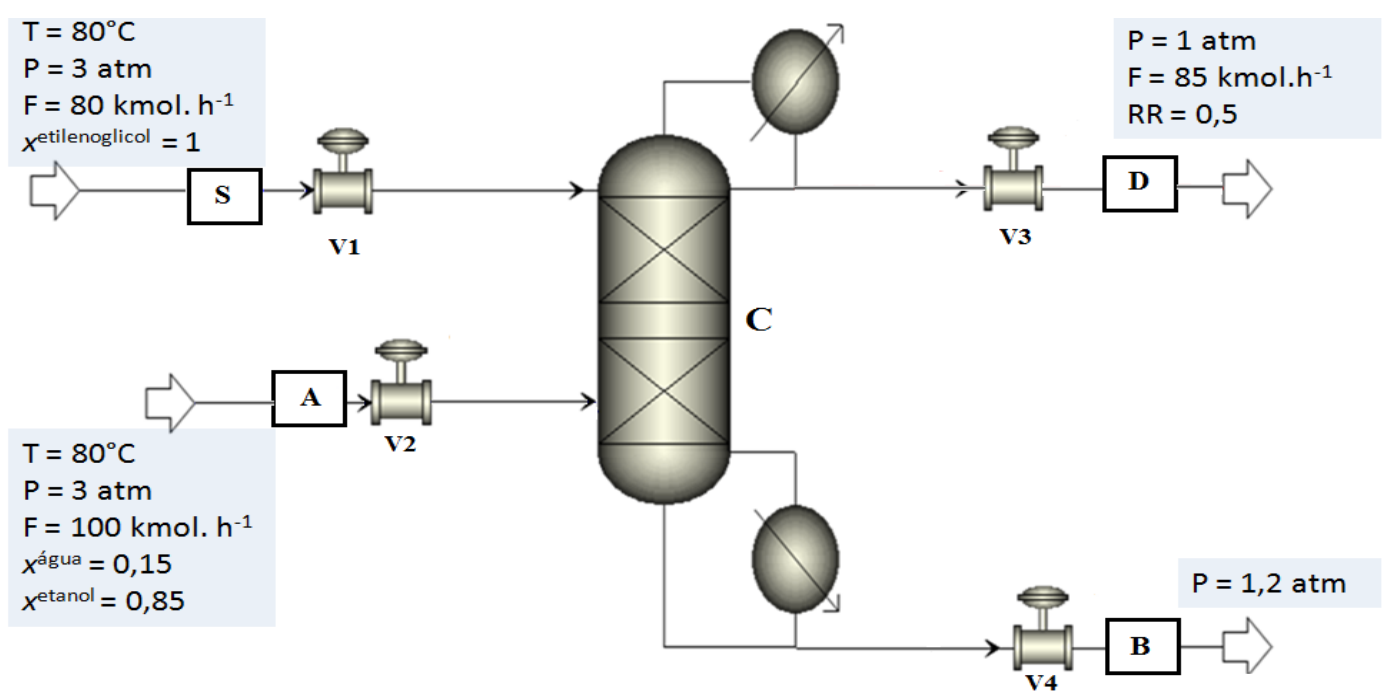

Figura 1 - Fluxograma do processo de destilação extrativa para desidratação do etanol.

Para a simulação da coluna foi usada a rotina RadFrac, a qual realiza cálculos rigorosos de operações multi-estágios de fracionamento líquido-vapor. Tal coluna é composta por 24 estágios, na qual é introduzida a corrente de alimentação da mistura azeotrópica etanol-água (A) no estágio 12 e no estágio 3 é introduzida a corrente do solvente (S), composta pelo etilenoglicol. Estas duas correntes entram em contato para serem separadas por destilação em duas novas correntes: a corrente de topo (D), na qual sai o etanol purificado e a corrente de fundo (B), a qual transporta o etilenoglicol juntamente com a água retirada do etanol ingressante. Conforme mostra a Figura 1, as variáveis especificadas foram a temperatura $(\mathrm{T})$, a pressão (P), a composição molar (x) e o fluxo molar (F) das correntes de alimentação da coluna. Além disso, especificou-se o fluxo molar do destilado e a razão de refluxo (RR). A pressão no topo e na base também foram especificadas. $\mathrm{O}$ modelo termodinâmico escolhido para a representação da fase líquida é o non-random two liquids (NRTL), por ajustar aos resultados experimentais (Meirelles et al.; 1992). 
Foi feita uma análise de sensibilidade para avaliar a influência de algumas variáveis tanto na fração molar do etanol do destilado quanto no consumo energético do refervedor $\left(\mathrm{Q}_{\mathrm{R}}\right)$. Em seguida, foi utilizada a ferramenta Model Analysis Tools/Optimization do Aspen Plus ${ }^{\circledR}$, tomando como função objetivo $\left(\mathrm{F}_{\mathrm{obj}}\right)$ a minimização da carga térmica do refervedor (Equação 1), obedecendo às restrições de acordo com as Equações 2 e 3 para a composição molar do etanol $\left(x_{D}^{E O H}\right)$ e sua fração molar recuperada $\left(F R_{D}^{E O H}\right)$ no destilado:

$\mathrm{F}_{\text {obj }}=\operatorname{minimizar}\left(\mathrm{Q}_{\mathrm{R}}\right)$

Sujeito a:

$$
\begin{aligned}
& x_{D}^{E O H} \geq 0,995 \\
& F R_{D}{ }^{E O H} \geq 0,999
\end{aligned}
$$

Após o procedimento de otimização no Aspen Plus ${ }^{\circledR}$, a simulação estacionária foi exportado para o Aspen Plus Dynamics ${ }^{\circledR}$ a fim de realizar simulações no estado transiente para avaliar as respostas do sistema mediante perturbações, as quais foram do tipo degrau com amplitude de $10 \%$, para mais e para menos em relação ao valor inicial da variável manipulada. A pressão da coluna tem efeito direto sobre a volatilidade relativa dos componentes chaves, então a pressão do topo da coluna foi mantida em seu set point de $1 \mathrm{~atm}$, assim como o nível do condensador e da base da coluna através de controladores PID.

\section{RESULTADOS}

De acordo com a Figura 2, os perfis de concentração possuem um comportamento bem atípico, quando comparados com a destilação convencional.
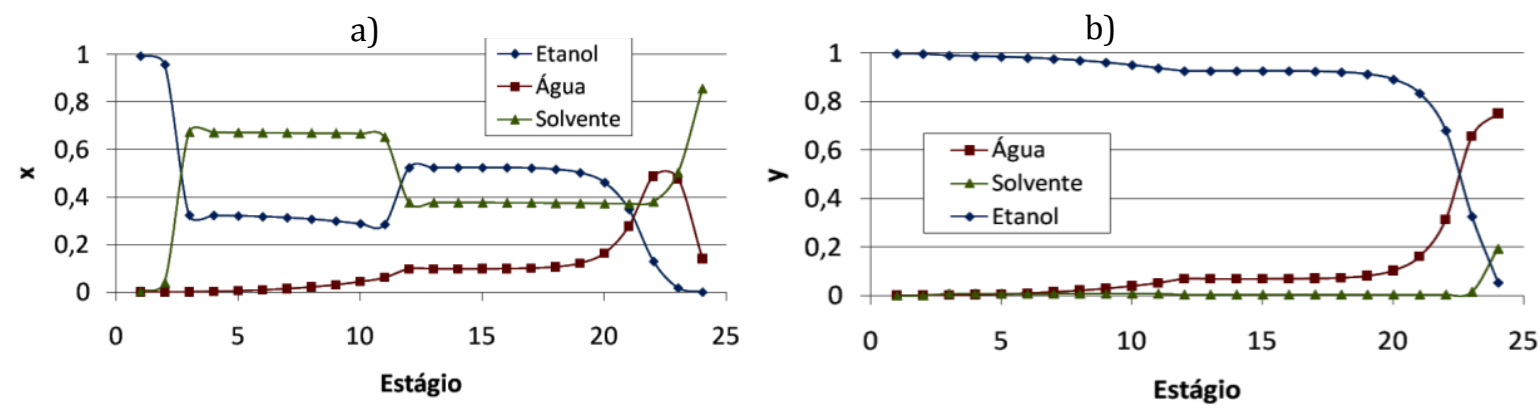

Figura 2 - Perfis de concentrações na coluna extrativa a) da fase líquida e b) da fase vapor.

Na Figura 2, a seção situada acima da introdução do solvente apresenta baixa fração molar líquida $(x)$ sem contribuir para a separação da água e do etanol. A segunda região, situada entre as alimentações do solvente e da mistura azeotrópica apresenta uma concentração praticamente constante de solvente na fase líquida, enquanto os demais componentes sofrem pequenas alterações de um ponto a outro. Já na região inferior da coluna, o solvente é diluído pela alimentação do azeótropo. A característica do perfil de concentração do solvente permite que a destilação extrativa seja tratada como se constituísse um sistema pseudobinário. A baixa fração de vapor (y) do solvente devido a sua baixa volatilidade relativa (Figura 2b), bem como as suas concentrações praticamente constantes em cada seção da coluna, possibilita o sistema ternário original ser reduzido ao sistema binário água-etanol. 


\subsection{Análise de sensibilidade}

Um máximo na composição para uma determinada razão de refluxo pode ser obtido quando o agente extrativo é alimentado no estágio 3 (Figura 3a). Além disso, a alimentação do etilenoglicol nesse estágio permite que a composição do etanol no destilado não seja muito afetada com alteração da razão de refluxo. Â medida que a localização do estágio de alimentação do etilenoglicol sobe em direção ao topo da coluna, aumenta a pureza do etanol no destilado até atingir um máximo e logo em seguida decresce. Essa diminuição é causada devido à vaporização de parte do etilenoglicol ao entrar na coluna, o qual se torna parte do vapor que flui para o condensador e que é retirado como destilado. No entanto, conforme ilustra a Figura 3b, a razão de refluxo deve ser a mais baixa possível para evitar desperdícios de energia durante a operação. Proporções de refluxo numa faixa de 0,4-0,5 atingem requisitos da composição do etanol desidratado com um menor consumo de energia no refervedor. Para uma razão de refluxo constante a carga térmica do refervedor praticamente não varia com a mudança do estágio de alimentação do solvente.

a)

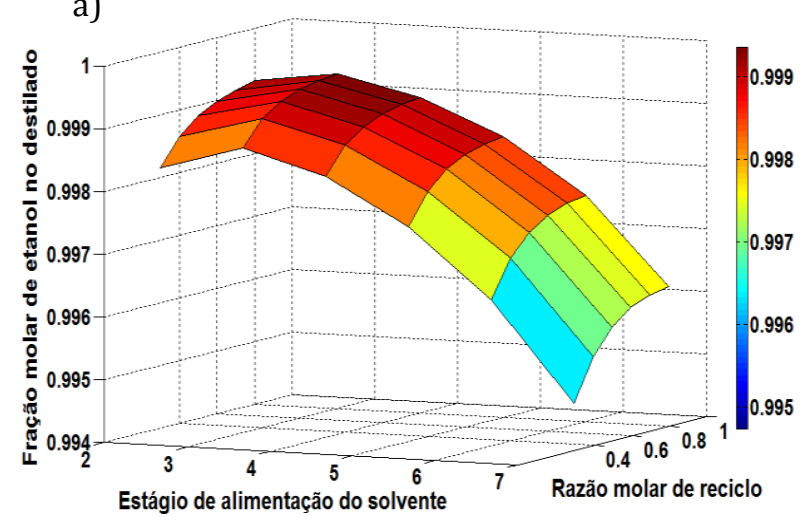

b)

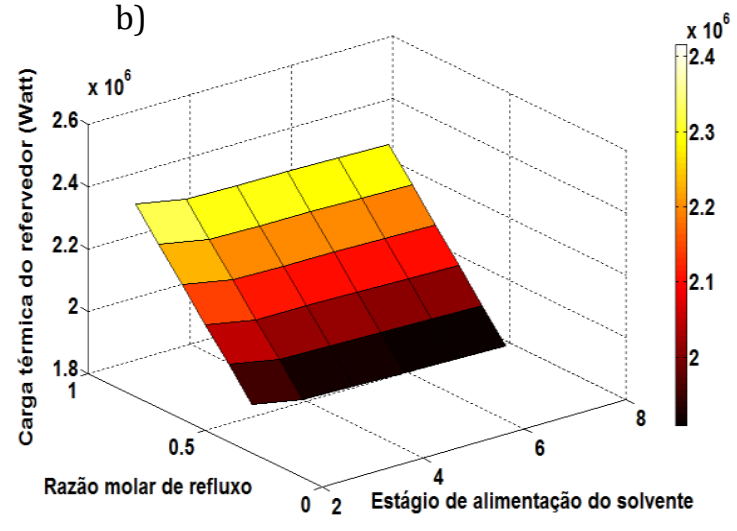

Figura 3 - Efeito da razão de refluxo e da localização do estágio de alimentação do solvente a) na fração molar de etanol no destilado e b) na carga térmica do refervedor.

A vazão de solvente provoca um efeito direto sobre a pureza do destilado. As análises de sensibilidade, apresentadas nas Figuras 4a e 4b, mostram que com o aumento da vazão de solvente é possível ter uma melhoria importante na qualidade do produto, sem afetar consideravelmente o consumo de energia. O líquido trazido pelo refluxo, o qual é rico em etanol, deve ser vaporizado enquanto que solvente deve permanecer na fase líquida. Isso oferece uma explicação para o maior efeito causado pela razão de refluxo na carga térmica do refervedor. Além disso, aumentar o refluxo conduz à diluição do solvente e consequentemente reduz o seu efeito extrativo. Por conseguinte, a razão de refluxo deve ser operada no menor valor possível.

Como pode ser observada na Figura 5a, a elevação na temperatura de alimentação do solvente exige um aumento na razão de refluxo para atender as especificações do destilado, consequentemente aumenta o consumo de energia (Figura 5b). Como a temperatura do solvente aumenta, então parte da água vaporiza, aumentando a vazão de água no destilado e diminuindo a sua pureza. 

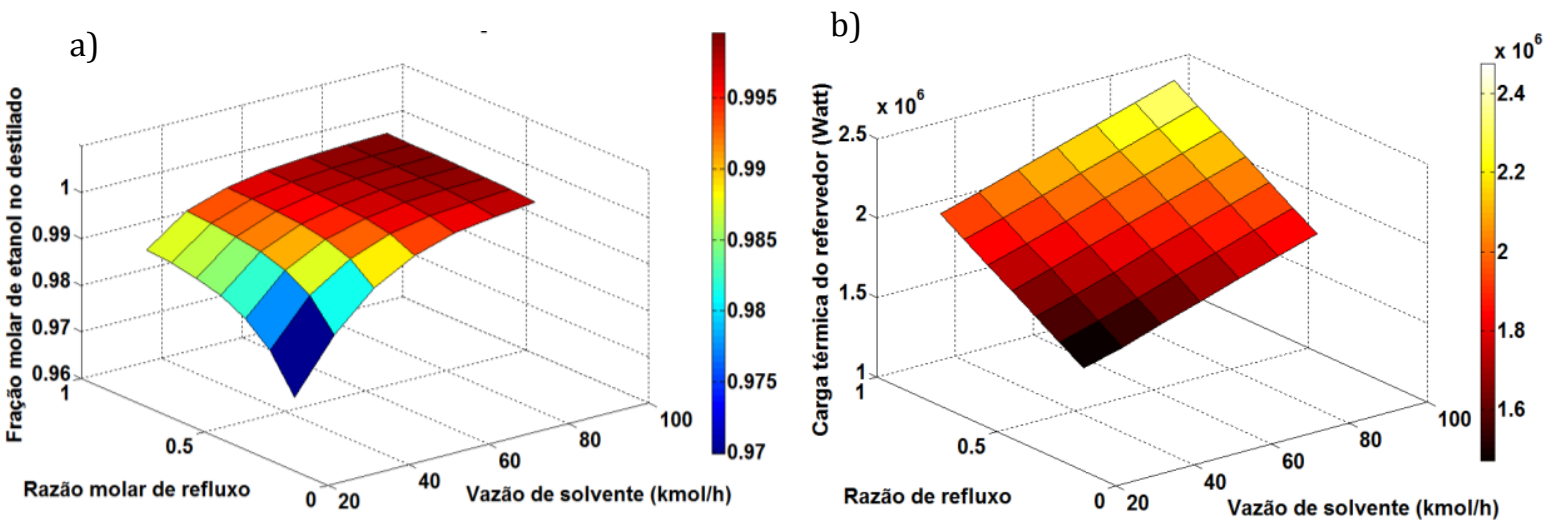

Figura 4 - Efeito da razão de refluxo e da vazão de solvente a) na fração molar de etanol no destilado e b) na carga térmica do refervedor.

Dessa forma, aumentar a taxa de refluxo é necessário para compensar esse efeito. Para refluxos baixos entre $0,4-0,5$ é necessário manter a temperatura entre 70 e $80{ }^{\circ} \mathrm{C}$ para manter a pureza do destilado em $99,5 \%$ de etanol.
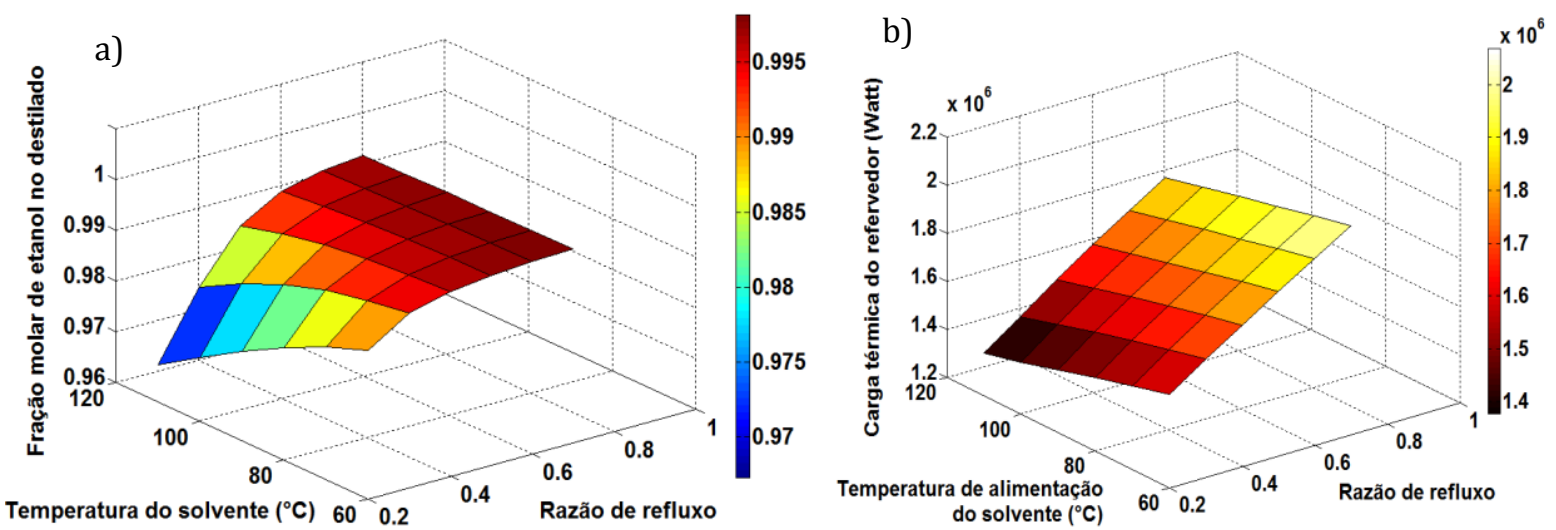

Figura 5 - Efeito da razão de refluxo e da vazão de solvente a) na fração molar de etanol no destilado e b) na carga térmica do refervedor.

\subsection{Otimização}

Para otimizar o processo, foram utilizadas, em conjunto, duas ferramentas do Aspen Plus ${ }^{\circledR}$ : Optimization e Sensitivity. Isso porque as variáveis: estágio de alimentação do solvente e estágio de alimentação do azeótropo não são contínuas, ou seja, Optimization não trabalha com variáveis discretas.

Com auxílio de uma análise de sensibilidade, gerou-se um conjunto de resultados ótimos para cada combinação entre estágio de alimentação do solvente e do azeótropo. Em seguida, foi escolhida a condição de processo em que a carga térmica do refervedor fosse à mínima possível. Logo, as condições operacionais da coluna de destilação extrativa foram estabelecidas de acordo com os resultados obtidos na otimização.

Algumas variáveis tiveram seus valores comparados antes e depois da otimização do processo conforme mostra a Tabela 1 . Foi possível reduzir a carga térmica do refervedor em $9,6 \%$. 
Tabela 1 - Resultados da otimização

\begin{tabular}{c|c|c}
\hline Variáveis & Valor inicial & Valor otimizado \\
\hline Temperatura do solvente $\left({ }^{\circ} \mathrm{C}\right)$ & 80 & 108,0 \\
Vazão do solvente $\left(\mathrm{kmol}^{-1} \mathrm{~h}^{-1}\right)$ & 80 & 73,37 \\
Estágio de alimentação do solvente & 3 & 4 \\
Estágio de alimentação azeótropo & 12 & 18 \\
Razão de refluxo & 0,5 & 0,43 \\
Carga térmica do refervedor $(\mathrm{W})$ & 1817027,81 & 1642586,36 \\
\hline
\end{tabular}

\subsection{Regime transiente}

A estratégia mais comum para controlar a qualidade do produto de topo de uma coluna de destilação é modular a vazão de refluxo da coluna. A Figura 6a mostra que o aumento da razão de refluxo aumenta a pureza do etanol no topo, pois a destilação alcança a separação das substâncias devido ao contato em contracorrente de vapor e líquido. Como o refluxo é composto basicamente por água e etanol, esse aumento faz com que a carga térmica do refervedor não seja suficiente para vaporizar a quantidade de água a mais que está descendo, ocasionando uma redução da temperatura na base (Figura 6e).
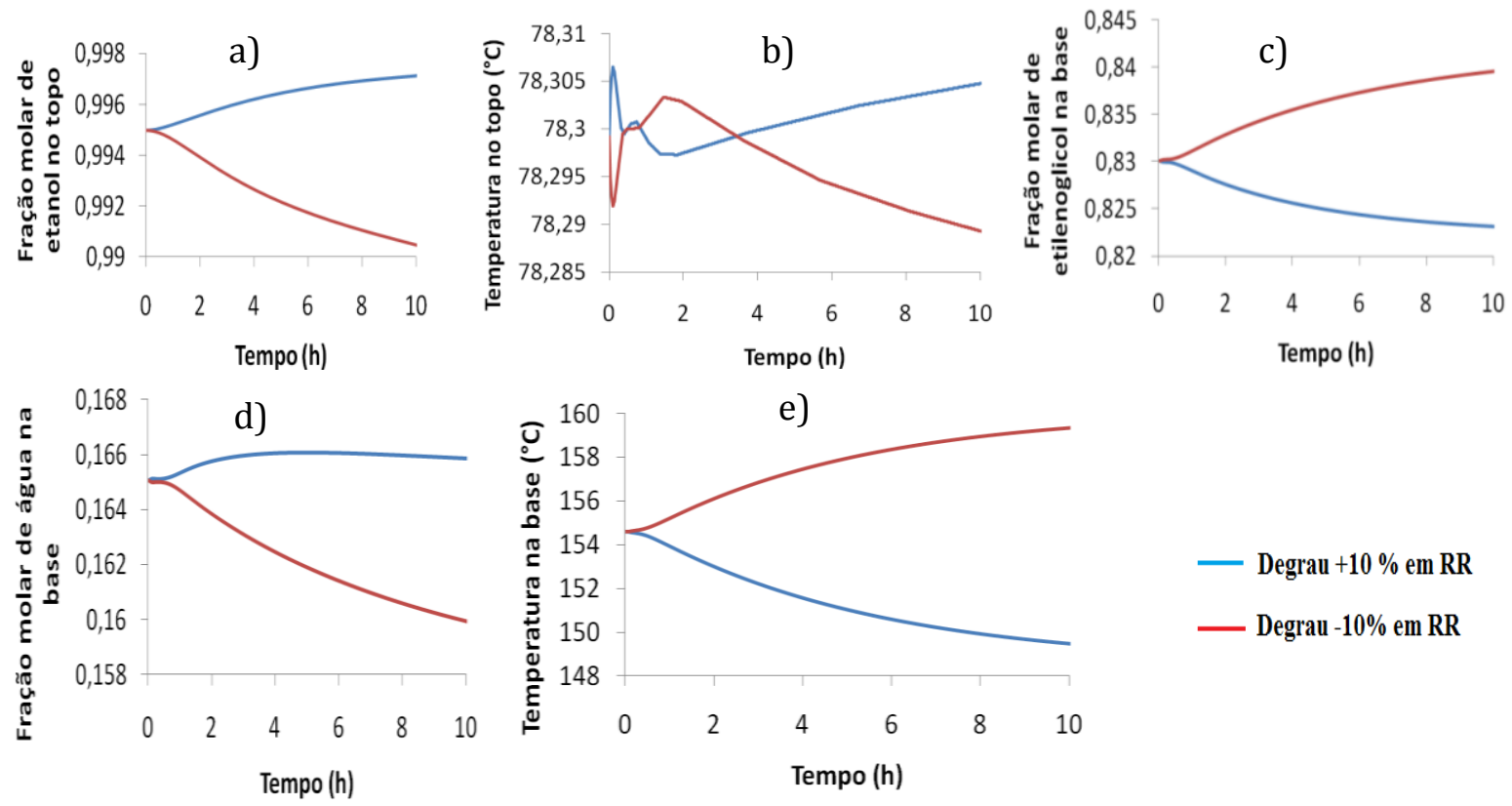

Figura 6 - Efeito da razão de refluxo na fração molar e temperatura do topo (a, b), na fração molar e temperatura da base (c, d, e).

Um comportamento contrário é observado quando se reduz a razão de refluxo na coluna. Com o excesso de carga térmica, uma quantidade significante de água vaporiza e sobe, o faz com que a fração de solvente na base aumente (Figura 6c). Comportamento análogo ao da Figura 6 pode ser obtido com a variação na vazão de alimentação do solvente.

Com o aumento do fluxo de alimentação de solvente, houve um aumento na fração de etanol no topo da coluna, pois o etilenoglicol tem a capacidade de alterar os coeficientes de 
atividade, melhorando a separação. Essa perturbação aumenta a quantidade de líquido na coluna, diminuindo a temperatura na base e aumentando a fração molar de solvente na corrente do fundo, semelhante às Figuras 6 e e $6 c$, respectivamente. Enquanto que com a redução da vazão de solvente, a pureza do etanol no topo diminui. Isso aconteceu porque o equilíbrio foi alterado e também porque a carga térmica do refervedor tornou-se elevada, vaporizando parte da água que antes saia pela base e diminuindo sua fração molar nessa região. A temperatura do topo praticamente não sofre influência da perturbação na vazão de solvente, o mesmo acontece com a variação na razão de refluxo (Figura 6b).

A carga térmica do refervedor é uma importante variável manipulada visto que é a principal fonte de calor da coluna. O seu aumento gera um deslocamento de componentes mais pesados para o topo. Na prática, isso aumenta o fluxo de vapor no interior da coluna. Esse incremento do fluxo de vapor tende a reduzir o tempo de contato entre as fases, o que impede que as fases líquidas e vapor interajam entre si por mais tempo, afetando os fenômenos de transferência de massa e calor e influenciando na eficiência do processo. A redução da carga térmica pouco influência na pureza do etanol no topo (Figura 7a), porém faz com que haja perda desse componente pela base. Isso pode ser verificado pela redução da fração tanto de água quanto de etilenoglicol nessa região de acordo com as Figuras 7c e 7d. A Figura 7 e mostra que o aumento da temperatura é devido ao aumento da carga térmica do refervedor e vice-versa.
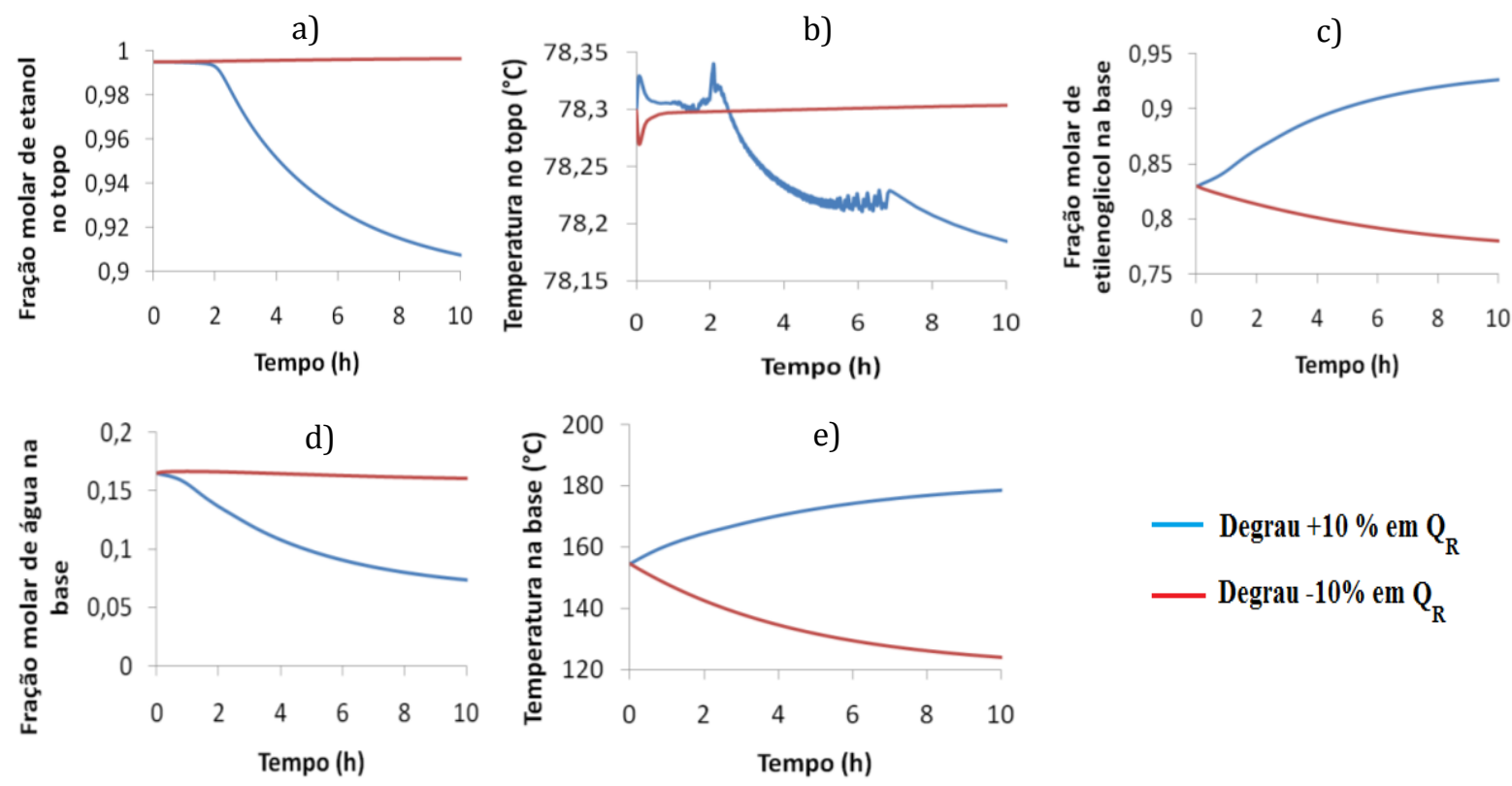

Figura 7 - Efeito da carga térmica do refervedor na fração molar e temperatura do topo $(a, b)$, na fração molar e temperatura da base $(c, d, e)$.

\section{CONCLUSÃO}

A otimização possibilitou obter o etanol anidro com uma fração molar de $99,5 \%$ no destilado, com o mínimo de desperdício pela base da coluna extrativa e com um mínimo consumo de energia, o qual foi reduzido em cerca de $9,6 \%$ em relação ao processo inicial baseado em dados da literatura. 
Os resultados obtidos mostram que a manipulação na carga térmica do refervedor é um fator crucial tanto na qualidade da separação quanto na redução de gastos energéticos. Fato importante tanto para planejamento de perturbações quanto para estudos relacionados à otimização energética do processo.

Observou-se também que o comportamento dinâmico do processo de destilação extrativa foi lento. Podendo ser explicado por ser uma separação de alta pureza, além disso, a separação é realizada em vários estágios e à medida que o processo é perturbado ocorrem mudanças em cada estágio dando um novo ponto de equilíbrio. Essa dinâmica é propagada por toda a coluna e o resultado final consiste em um tempo de resposta muito elevado, além de comportamento não linear.

\section{REFERÊNCIAS}

DIAS, M.; ENSINAS, A.; NEBRA, S.; MACIEL FILHO, R.; ROSSELL, C.; WOLF, M. Production of bioethanol and other bio-based materials from sugarcane bagasse: Integration to conventional bioethanol production process. Chem. Eng. Res. Des., v. 87, p. 1206-1216, 2009.

ENGELIEN, K.; SKOGESTAD, S. Selecting appropriate control variables for a heat integrated distillation system with prefractionator. Comput. Chem. Eng., v. 28, n. 5, p. 683-691, 2004.

GIL, I. D.; UYAZÁN, A. M.; AGUILAR, J. L.; RODRÍGUEZ, G.; CAICEDO, L. A. Separation of ethanol and water by extractive distillation with salt and solvent as entrainer: process simulation. Braz. J. Chem. Eng., v. 25, n. 1, p. 207-215. 2008.

GIL I.D., J.M. GÓMEZ, G. RODRÍGUEZ, Control of an extractive distillation process to dehydrate ethanol using glycerol as entrainer, Comp. Chem. Eng., v. 39, p. 129-142, 2012.

JUNQUEIRA, T. L.; DIAS, M. O. S.; MACIEL, M. R. Wolf; MACIEL FILHO, R. ; ROSSELL, C. E.V. Simulation of anhydrous bioethanol production process using efficiency correlations for conventional and extractive distillation. Distillation \& Absorption, p. 521-526, 2012.

MEIRELLES, A.; WEISS, S.; HERFURTH, H. Ethanol dehydration by extractive distillation. J. Chem. Technol. Biotechnol., v.56, p.181-188, 1992.

OLIVEIRA, A. C.; GON, T. C. R.; MARRAFON, R. D.; REIS, M. H. M. Simulação do processo de destilação extrativa para produção de álcool anidro com diferentes solventes. In: VIII CONGRESSO BRASILEIRO DE ENGENHARIA QUÍMICA EM INICIAÇÃO CIENTÍFICA, 2009, Uberlândia. Anais... Uberlância: COBEQ-IC, 2009.

SEADER, J.D.; HENLEY, E.J. Separation Process Principles. 1 ed. New York: John Wiley \& Sons, 1998.

WOLF, M.; BRITO, R. Evaluation of the dynamic behavior of an extractive column for dehydration of aqueous ethanol mixtures. Comput. Chem. Eng., v. 19, p. 405-408, 1995. 